\title{
Association Between Inhaled Corticosteroid Use and the Severe Acute Respiratory Syndrome Coronavirus 2 Infection: A Nationwide Population- based Study in South Korea
}

\author{
Sang Chul Lee \\ National Health Insurance Service Ilsan Hospital \\ Kang Ju Son \\ National Health Insurance Service Ilsan Hospital \\ Chang Hoon Han \\ National Health Insurance Service Ilsan Hospital \\ Ji Ye Jung \\ Yonsei University College of Medicine https://orcid.org/0000-0003-1589-4142 \\ Seon Cheol Park ( $\square$ parksc@nhimc.or.kr) \\ National Health Insurance Service Ilsan Hospital
}

\section{Research}

Keywords: Inhaled corticosteroid, severe acute respiratory syndrome coronavirus 2, chronic respiratory diseases, risk

Posted Date: September 9th, 2020

DOI: https://doi.org/10.21203/rs.3.rs-72221/v1

License: (c) (i) This work is licensed under a Creative Commons Attribution 4.0 International License.

Read Full License 


\section{Abstract \\ Background}

Inhaled corticosteroid (ICS) use may increase the risk of respiratory infection, but its influence on the risk of severe acute respiratory syndrome coronavirus 2 (SARS-CoV-2) infection is not known. This study aimed to investigate the association between ICS use and the risk of SARS-CoV-2 infection among the patients with chronic respiratory diseases.

\section{Methods}

The Ministry of Health and Welfare and Health Insurance Review and Assessment Service in Korea provided nationwide data of 44,968 individuals with chronic respiratory diseases tested for SARS-CoV-2 until May 15. The risks of SARS-CoV-2 infection were retrospectively analysed according to the prescription, type, and dose of ICS taken one year before SARS-CoV-2 test.

\section{Results}

Among 44,968 individuals tested, 931 (2.1\%) were positive for SARS-CoV-2. A total of 7,019 patients (15.6\%) were prescribed ICS one year prior to being tested for SARS-CoV-2. Low, medium, and high doses of ICS were prescribed in $7.5 \%, 1.6 \%$, and $6.5 \%$ of total cases, respectively. Among the types of ICS, budesonide, fluticasone, beclomethasone, and ciclesonide were prescribed in $3.7 \%, 8.9 \%, 2.3 \%$, and $0.6 \%$ of total cases, respectively. The multivariate analysis showed no significant increase in infection with ICS use (OR, $0.84 ; 95 \% \mathrm{Cl}, 0.66-1.03)$. Moreover, there were no associations between the risk of infection, and doses or types of ICS prescribed.

\section{Conclusion}

Prior ICS use did not increase the risk of SARS-CoV-2 infection. Moreover, different doses or types of ICS did not affect the risk. This study supports the current guidelines to manage patients taking ICS during the SARS-CoV-2 pandemic.

\section{Background}

At the end of December 2019, an unexplained pneumonia emerged in Wuhan, in the Hubei Province, China. This disease was found to be caused by a novel coronavirus, severe acute respiratory syndrome coronavirus 2 (SARS-CoV-2). [1] As of June 1, 2020, SARS-CoV-2 has resulted in over 6 million infections and 370,000 deaths worldwide. [2] Patients with SARS-CoV-2 often recover from mild symptoms such as fever or cough, but some die from severe complications. [3] In patients with SARS-CoV-2, the presence of 
respiratory disease was associated with poor prognosis, and chest computed tomography showed abnormalities in $86.2 \%$ of hospitalized patients. $[4,5]$

Inhaled corticosteroids (ICS) are essential drugs for major respiratory diseases such as asthma or chronic obstructive pulmonary disease (COPD). However, ICS may increase the risk of respiratory infection. In COPD patients, a meta-analysis reported that the use of ICS alone or in combination may increase the risk of pneumonia. [6] Regarding asthma, some studies have reported that ICS use may increase the risk of pneumonia, although this is controversial. $[7,8]$ The ICS may also increase the risk of tuberculosis or nontuberculous mycobacterial infection. $[9,10]$

ICS are frequently prescribed to patients with respiratory diseases who may be at a high risk for severe SARS-CoV-2 infection. The purpose of this study was to evaluate the association between ICS use and the risk of SARS-CoV-2 infection in patients with chronic respiratory diseases.

\section{Methods}

\section{Data source}

For a global research collaboration on SARS-COV-2, the Ministry of Health and Welfare and Health Insurance Review and Assessment Service (HIRA) of Korea have shared the nationwide data of SARSCoV-2 with researchers. The HIRA dataset was based on the insurance benefit claim sent to the HIRA and comprised of all cases tested for SARS-CoV-2 in Korea. This dataset includes various health-related variables, which comprise socio-demographic information, health care utilization including diagnosis and medications, and survival status.

\section{Case definition}

Among the total 69,792 individuals tested for SARS-CoV-2, 44,968 subjects who have accompanied comorbidity of chronic respiratory diseases (asthma, J45-46; COPD, J43-44; bronchiectasis J47; according to the International Classification of Diseases, Tenth Revision) in the first year before the test of SARS-CoV-2, were included in this study using HIRA dataset until May 15, 2020. The patients with SARS-CoV-2 infection were identified by the following diagnostic codes: coronavirus infection (B342); coronavirus as the cause of diseases classified to other chapters (B972); domestic temporary designation or emergency use of new diseases (B18); novel coronavirus infection (U181); coronavirus disease 2019 (U071). Those without the above codes were considered as negative controls for SARS-COV-2 infection.

\section{Demographic factors}

Information on sex, age, region of residence, and medical aid were taken at the time of SARS-CoV-2 diagnosis. Data regarding comorbidity and ICS prescription were collected during the first year before the test of SARS-CoV-2. The Charlson Comorbidity Index $(\mathrm{CCl})$, which is used for stratifying the risk of mortality or the resource use of patients based on comorbidities, was recorded as previously described. [11] Comorbidities were categorized into heart disease (ischemic heart disease, 120-25; congestive heart 
failure, I50), diabetes mellitus (E10-14), hypertension (110), and cancer (C00-97) according to the International Classification of Diseases, Tenth Revision.

\section{Outcomes}

Among all individuals tested for SARS-CoV-2, the case group included patients with SARS-CoV-2 infection and the control group included patients without SARS-CoV-2 infection. The risks of SARS-CoV-2 infection were analysed according to the prescription, type, and dose of ICS taken one year before the SARS-CoV-2 test. The type of ICS was categorized into budesonide, fluticasone, beclomethasone, and ciclesonide. The dose of ICS was calculated as the average daily consumption and categorized into low, medium, and high doses according to the Global Initiative for Asthma (GINA) report. [12]

\section{Statistical analysis}

Descriptive statistics were performed for all variables. Differences between the two groups were assessed by the chi-squared test for categorical variables. Multiple logistic regression analysis was performed to determine whether ICS was associated with the risk of SARS-CoV-2 infection. Three models were used to analyse the risk of infection according to the ICS prescription, type, and dose. The risk of infection is presented as the odds ratio (OR) with 95\% confidence interval (Cl). A $P$-value $<0.05$ was considered statistically significant. All statistical analyses were performed with SAS, version 9.4 (SAS Institute, Cary, NC, USA).

\section{Results}

\section{Baseline demographics of individuals tested for SARS-CoV- 2}

A total of 44,968 individuals were included and 931 (2.1\%) were positive for SARS-CoV-2 (Table 1). A total of $355(0.7 \%)$ males and $576(1.3 \%)$ females were positive for SARS-CoV-2. In terms of the age group, a higher proportion of individuals aged between $60-79$ years (32.3\%) tested for SARS-CoV-2, followed by individuals aged between $40-59$ years (19.8\%) and $20-39$ years $(19.5 \%)$. The rate of SARS-CoV-2 infection was also higher in these age groups. When comparing the 16 regions (cities and provinces) in South Korea, there were high rates of SARS-CoV-2 infection in the South-Eastern region. In Seoul, the number of SARS-CoV-2 cases was relatively low considering the large number of individuals tested. Among the four types of comorbidities, patients with any comorbidity tended to have a lower probability of SARS-CoV-2 infection in the univariate analysis. This trend was similar in the analysis according to $\mathrm{CCl}$, and the higher the $\mathrm{CCl}$, the lower the probability of SARS-CoV-2 infection. 
Table 1

Baseline demographics of individuals tested for SARS-CoV-2

\begin{tabular}{|c|c|c|c|c|}
\hline Variable & $\begin{array}{l}\text { Total } \\
(n=44,968)\end{array}$ & $\begin{array}{l}\text { Positive for } \\
\text { SARS-CoV-2 ( } n= \\
\text { 931) }\end{array}$ & $\begin{array}{l}\text { Negative for } \\
\text { SARS-CoV-2 ( } n= \\
44,037)\end{array}$ & $\begin{array}{l}P \\
\text { value }\end{array}$ \\
\hline Male & $\begin{array}{l}22,210 \\
(49.4)\end{array}$ & $355(38.1)$ & $21,855(49.6)$ & $\begin{array}{l}< \\
0.001\end{array}$ \\
\hline Age (y) & & & & $<.001$ \\
\hline $0-19$ & $5,363(11.9)$ & $62(6.7)$ & $5,301(12.0)$ & \\
\hline $20-39$ & $8,753(19.5)$ & $205(22.0)$ & 8,548 (19.4) & \\
\hline $40-59$ & $8,901(19.8)$ & 269 (28.9) & $8,632(19.6)$ & \\
\hline $60-79$ & $\begin{array}{l}14,546 \\
(32.3)\end{array}$ & $298(32.0)$ & $14,248(32.4)$ & \\
\hline$\geq 80$ & $7,405(16.5)$ & $97(10.4)$ & $7,308(16.6)$ & \\
\hline Region of residence & & & & $\begin{array}{l}< \\
0.001\end{array}$ \\
\hline \multicolumn{5}{|l|}{ North-western } \\
\hline Seoul $^{*}$ & $\begin{array}{l}13,114 \\
(29.2)\end{array}$ & $72(7.7)$ & $13,042(29.6)$ & \\
\hline Incheon* & $2,341(5.2)$ & $18(1.9)$ & 2,323 (5.3) & \\
\hline Daejeon $^{*}$ & $1,557(3.5)$ & $11(1.2)$ & $1,546(3.5)$ & \\
\hline Gyeonggi $^{\dagger}$ & $9,463(21.0)$ & $72(7.7)$ & $9,391(21.3)$ & \\
\hline Chungcheongbuk $^{\dagger}$ & $1,175(2.6)$ & $21(2.3)$ & $1,154(2.6)$ & \\
\hline Chungcheongnam $^{\dagger}$ & $2,523(5.6)$ & $46(4.9)$ & $2,477(5.6)$ & \\
\hline \multicolumn{5}{|l|}{ North-eastern } \\
\hline Gangwon $^{+}$ & $1,127(2.5)$ & $21(2.3)$ & $1,106(2.5)$ & \\
\hline
\end{tabular}

Values are presented as number (\%).

SARS-CoV-2, severe acute respiratory syndrome coronavirus 2 .

${ }^{*}$ Cities in South Korea

${ }^{\dagger}$ Provinces in South Korea 


\begin{tabular}{|c|c|c|c|c|}
\hline Variable & $\begin{array}{l}\text { Total } \\
(n=44,968)\end{array}$ & $\begin{array}{l}\text { Positive for } \\
\text { SARS-CoV-2 ( } n= \\
931)\end{array}$ & $\begin{array}{l}\text { Negative for } \\
\text { SARS-CoV-2 ( } n= \\
44,037)\end{array}$ & $\begin{array}{l}P \\
\text { value }\end{array}$ \\
\hline \multicolumn{5}{|l|}{ South-eastern } \\
\hline Daegu $^{*}$ & $4,370(9.7)$ & $422(45.3)$ & $3,948(8.9)$ & \\
\hline Busan $^{*}$ & $2,515(5.6)$ & $15(1.6)$ & $2,500(5.7)$ & \\
\hline Ulsan* & $742(1.7)$ & $4(0.4)$ & $738(1.7)$ & \\
\hline Gyeongsangbuk $^{\dagger}$ & $1,626(3.6)$ & $153(16.4)$ & $1,473(3.3)$ & \\
\hline Gyeongsangnam $^{\dagger}$ & $1,585(3.5)$ & $36(3.9)$ & $1,549(3.5)$ & \\
\hline \multicolumn{5}{|l|}{ South-western } \\
\hline Gwangju* $^{*}$ & $712(1.6)$ & $11(1.2)$ & $701(1.6)$ & \\
\hline Jeollabuk $^{\dagger}$ & $1,082(2.4)$ & $23(2.5)$ & $1,059(2.4)$ & \\
\hline Jeollanam $^{+}$ & $712(1.6)$ & $6(0.6)$ & $706(1.6)$ & \\
\hline Jeju Island $^{+}$ & $324(0.7)$ & $0(0)$ & $324(0.7)$ & \\
\hline $\begin{array}{l}\text { Medical-aid } \\
\text { beneficiaries }\end{array}$ & $3,897(8.7)$ & $82(8.8)$ & $3,815(8.7)$ & 0.877 \\
\hline \multicolumn{5}{|l|}{ Comorbidities } \\
\hline Heart disease & $9,508(21.1)$ & $121(13.0)$ & $9,387(21.3)$ & $<.001$ \\
\hline Diabetes mellitus & $\begin{array}{l}13,371 \\
(29.7)\end{array}$ & $210(22.6)$ & $13,161(29.9)$ & $<.001$ \\
\hline Hypertension & $\begin{array}{l}18,182 \\
(40.4)\end{array}$ & $294(31.6)$ & $17,888(40.6)$ & <. 001 \\
\hline Cancer & $7,092(15.8)$ & $63(6.8)$ & $7,029(15.9)$ & <. \\
\hline \multicolumn{4}{|c|}{ Charlson comorbidity index } & < 0.001 \\
\hline \multicolumn{5}{|c|}{ Values are presented as number (\%). } \\
\hline \multicolumn{5}{|c|}{ SARS-CoV-2, severe acute respiratory syndrome coronavirus 2 . } \\
\hline \multicolumn{5}{|c|}{${ }^{*}$ Cities in South Korea } \\
\hline${ }^{\dagger}$ Provinces in Sout & & & & \\
\hline
\end{tabular}




\begin{tabular}{|c|c|c|c|c|}
\hline Variable & $\begin{array}{l}\text { Total } \\
(n=44,968)\end{array}$ & $\begin{array}{l}\text { Positive for } \\
\text { SARS-CoV-2 ( } n= \\
931)\end{array}$ & $\begin{array}{l}\text { Negative for } \\
\text { SARS-CoV-2 ( } n= \\
44,037)\end{array}$ & $\begin{array}{l}P \\
\text { value }\end{array}$ \\
\hline 1 & $\begin{array}{l}15,084 \\
(33.5)\end{array}$ & $374(40.2)$ & $14,710(33.4)$ & \\
\hline 2 & $7,636(16.9)$ & $182(19.6)$ & $7,454(16.9)$ & \\
\hline$\geq 3$ & $\begin{array}{l}22,248 \\
(49.5)\end{array}$ & $375(40.3)$ & $21,873(49.7)$ & \\
\hline \multicolumn{5}{|c|}{ Values are presented as number (\%). } \\
\hline \multicolumn{5}{|c|}{ SARS-CoV-2, severe acute respiratory syndrome coronavirus 2 . } \\
\hline \multicolumn{5}{|c|}{${ }^{*}$ Cities in South Korea } \\
\hline
\end{tabular}

\section{Patterns of ICS use in the past one year}

A total of 7,019 patients (15.6\%) were prescribed ICS one year prior to being tested for SARS-CoV-2 (Table 2). Low, medium, and high doses of ICS were prescribed in $7.5 \%, 1.6 \%$, and $6.5 \%$ of total cases, respectively. Budesonide, fluticasone, beclomethasone, and ciclesonide were prescribed in $3.7 \%, 8.9 \%$, $2.3 \%$, and $0.6 \%$ of total cases, respectively. 
Table 2

Patterns of inhaled corticosteroid use in the past one year

\begin{tabular}{|c|c|c|c|c|}
\hline Variable & $\begin{array}{l}\text { Total } \\
(n=44,968)\end{array}$ & $\begin{array}{l}\text { Positive for } \\
\text { SARS-CoV-2 } \\
(n=931)\end{array}$ & $\begin{array}{l}\text { Negative for } \\
\text { SARS-CoV-2 } \\
(n=44,037)\end{array}$ & $P$-value \\
\hline Inhaled corticosteroid used & $7,019(15.6)$ & $114(12.2)$ & $6905(15.7)$ & 0.004 \\
\hline Dose & & & & $<0.001$ \\
\hline Low & $3,349(47.7)$ & $54(47.3)$ & $3,295(47.7)$ & \\
\hline Medium & $728(10.4)$ & $10(8.8)$ & 718 (10.4) & \\
\hline High & $2,942(41.9)$ & $50(43.9)$ & $2,892(41.9)$ & \\
\hline Type & & & & $<0.001$ \\
\hline Budesonide & $1,674(23.8)$ & $19(16.7)$ & $1,655(23.9)$ & \\
\hline Fluticasone & $4,001(57.0)$ & $76(66.7)$ & $3,925(56.9)$ & \\
\hline Beclomethasone & $1,054(15.1)$ & $13(11.4)$ & $1,041(15.1)$ & \\
\hline Ciclesonide & $290(4.1)$ & $6(5.2)$ & $284(4.1)$ & \\
\hline Values are presented as nun & ber (\%). & & & \\
\hline
\end{tabular}

\section{Multivariate analysis for ICS use and risk of SARS-CoV-2 infection}

A multivariate analysis was performed to assess whether ICS use was associated with SARS-CoV-2 infection (Table 3 and Supplement Table 1). In model 1, the individuals who were and were not taking ICS were compared. The risk of developing SARS-CoV-2 infection was not associated with taking ICS (OR = $0.84,95 \% \mathrm{Cl} 0.68-1.03)$. There was no association between the risk of SARS-CoV-2 infection and ICS dose in model 2. When analysing the risk of infection according to the ICS type, all types of ICS was not associated with risk of SARS-CoV-2 infection in model 3. 
Table 3

Multivariate analysis for inhaled corticosteroid use and risk of SARS-CoV-2

\begin{tabular}{|c|c|c|c|}
\hline Variable & Odds ratio* & $95 \%$ confidence interval & $P$-value \\
\hline \multicolumn{4}{|l|}{ ICS use } \\
\hline No & 1 & & \\
\hline Yes & 0.84 & $0.68-1.03$ & 0.089 \\
\hline \multicolumn{4}{|l|}{ ICS dose } \\
\hline No & 1 & & \\
\hline Low & 0.83 & $0.63-1.11$ & 0.204 \\
\hline Medium & 0.75 & $0.39-1.42$ & 0.373 \\
\hline High & 0.87 & $0.64-1.17$ & 0.347 \\
\hline \multicolumn{4}{|l|}{ ICS type } \\
\hline No & 1 & & \\
\hline Budesonide & 0.67 & $0.42-1.08$ & 0.098 \\
\hline Fluticasone & 0.86 & $0.67-1.09$ & 0.227 \\
\hline Beclomethasone & 0.88 & $0.50-1.56$ & 0.679 \\
\hline Ciclesonide & 1.33 & $0.58-3.09$ & 0.503 \\
\hline \multicolumn{4}{|c|}{$\begin{array}{l}\text { *Adjusted for sex, age, region of residence, medical-aid beneficiary, respiratory disease, heart diseas } \\
\text { diabetes mellitus, hypertension, and Charlson comorbidity index. }\end{array}$} \\
\hline
\end{tabular}

\section{Discussion}

ICS plays an important role in controlling airway diseases such as asthma and COPD by reducing airway inflammation. However, the increased risk of infection with the use of ICS has always been a concern. Although the mechanism has not been fully elucidated, the immunosuppressive effects of ICS are speculated to be associated with the locally high concentration of ICS in the respiratory tract. [13] As ICS is often regarded as being immunosuppressive and associated with an increased risk of respiratory infection, many physicians are concerned about an increased risk of SARS-CoV-2 infection in patients with airway diseases taking ICS. Furthermore, whether such patients should continue using ICS during the SARS-CoV-2 pandemic is unclear. Our study showed that ICS did not increase the risk of SARS-CoV-2 infection. Furthermore, risk of SARS-CoV-2 infection was not associated with doses and types of ICS.

These effects have raised concerns about an increased risk of respiratory infection, including upper respiratory tract infection (URTI), pneumonia, and mycobacterial pulmonary disease. Two meta-analyses 
reported that ICS was associated with a significantly increased risk of URTI in patients with asthma or COPD. $[14,15]$ Only high-dose ICS increased the risk of URTI $(O R=1.19)$ in patients with COPD, while lowdose $(O R=1.46)$ and high-dose $(O R=1.20)$ ICS increased the risk of URTI in patients with asthma. Singanayagam et al. reported that ICS impairs innate and acquired antiviral immune responses leading to delayed virus clearance. They also found previously unrecognized adverse effects such as enhanced mucus production, impaired antimicrobial peptide secretion, and increased pulmonary bacterial load during virus-induced exacerbations, which increased risk of pneumonia after clearance of the viral infection. [16] Several studies and a meta-analysis have demonstrated an increased risk of pneumonia with ICS use in COPD patients, although this increased risk of pneumonia did not lead to increased mortality. [6] However, ICS use and pneumonia in asthma patients have shown controversial results, which might owe to the varying age range and comorbidities assessed in different studies. $[7,8,17]$ ICS also increased the infection risk of both nontuberculous and tuberculous mycobacterial pulmonary diseases. $[9,10,18]$ There was a strong dose-response relationship between mycobacterial infection and the cumulative ICS dose. [18]

Cell entry of coronaviruses depends on binding of the viral spike (S) proteins to cellular receptors and on $S$ protein priming by host cell proteases. SARS-CoV-2 uses the angiotensin converting enzyme 2 (ACE2) for entry and the transmembrane protease serine 2 (TMPRSS2) for $S$ protein priming. $[19,20]$ An increased expression in lung cells will increase susceptibility to SARS-CoV-2 infection or lead to a more severe COVID-19 disease. [21]

Peters et al. analysed gene expression of ACE2 in sputum cells from 330 participants in the Severe Asthma Research Program-3 and 79 healthy controls. They found that the use of ICS was associated with a decreased expression of ACE2 and TMPRSS2. [21] However, intramuscular triamcinolone acetonide injection did not lower expression of either genes. This discordant result between systemic corticosteroid and inhaled corticosteroid might be related to assessment of sputum cell gene expression at different time points after exposure to the corticosteroid. [21] They suggested that the decrease in ACE2 and TMPRSS2 gene expression provided some reassurance that ICS use will not increase the risk of SARS-CoV-2 infection or morbidity, although prospective studies are required to confirm this assumption. Moreover, the mechanism by which ICS reduces the expression of ACE2 and TMPRSS2 needs to be investigated further.

Type of ICS was not associated with risk of SARS-CoV-2. Iwabuchi et al reported cases of SARS-CoV-2 pneumonia successfully treated with ciclesonide inhalation. [22] However, it is not clear that whether these patients would have improved spontaneously because there was no control group. Nevertheless, there have been several reports that provide evidence for the beneficial effects of ICS in dealing with virus infections. [23] Matsuyama et al. showed that ICS ciclesonide blocks coronavirus RNA replication by targeting viral NSP15. [24] Moreover, glycopyrronium, formoterol, and a combination of glycopyrronium, formoterol, and budesonide inhibited human coronaviruses-229E replication partly by inhibiting receptor expression and/or endosomal function suggesting that these drugs may modulate infection-induced inflammation in the airway. [25] 
Previous studies reported that fluticasone use is associated with a higher risk of pneumonia than budesonide due to its greater and more protracted immunosuppressive effects locally, in the airways and lungs. $[15,18]$ Local pharmacokinetic profiles (e.g. rate and extent of airway/pulmonary absorption) of ICS are strongly associated with the intrinsic physicochemical properties of corticosteroids, such as lipophilicity, aqueous solubility, and airway epithelial permeability. [26] However, all the types of ICS did not increase the risk of SARS-CoV-2 infection in this study. The differences in pharmacokinetics and immune modulatory effects of each type of ICS warrants further study, to investigate the relationship between different types of ICS and the risk of SARS-CoV-2 infection.

This is the first report to demonstrate the relationship between the use of ICS and risk of SARS-CoV-2 infection in a large population-based study including different types of ICS. However, this study has several limitations. The severity of primary respiratory diseases for which ICS were prescribed was not categorized. The severity of respiratory disease would affect the degree of risk for SARS-CoV-2 infection. Secondly, previous use of systemic corticosteroid was not included in the analysis. Systemic corticosteroids are more potent immune modulators than ICS; therefore, its effects on the risk for SARSCoV-2 infection should be important. Thirdly, the risk of infection based on different types of ICS could not be fully evaluated because of the different number of each ICS prescribed. Lastly, this study included people who were suspected of or at a high risk of SARS-CoV-2 infection; therefore, asymptomatic infected persons could have been missed. Moreover, data were analysed until the middle of the pandemic period and from the administrative claims database; thus, this study does not represent the whole population who were suspected of having SARS-CoV-2, at a high risk of infection, and confirmed with SARS-CoV-2 in Korea.

\section{Conclusions}

In conclusion, prior use of ICS within one year did not increase the risk of SARS-COV-2 infection in Korea. Furthermore, different doses or types of ICS did not affect the risk of SARS-CoV-2 infection. This study supports the current guidelines that recommend no changes to the treatment or management of chronic respiratory conditions including asthma and COPD, and suggest continuing the use of ICS, even during the COVID-19 pandemic. Further epidemiologic studies with a large population are warranted to clarify the association between ICS use and the risk of SARS-CoV-2 infection, as well as their mechanisms.

\section{Abbreviations}

ACE2- Angiotensin converting enzyme 2

CCl- Charlson Comorbidity Index

Cl- Confidence interval

COPD-: Chronic obstructive pulmonary disease 
GINA- GLOBAL Initiative for Asthma

HIRA- Health Insurance Review and Assessment Service

ICS- Inhaled corticosteroid

OR- Odds ratio

SARS-CoV-2- Severe acute respiratory syndrome coronavirus 2

TMPRSS2- Transmembrane protease serine 2

URTI- Upper respiratory tract infection

\section{Declarations}

\section{Ethics approval and consent to participate:}

This study was approved by the Institutional Review Board of the National Health Insurance Service of the Ilsan Hospital and adhered to the tenets of the Declaration of Helsinki (NHIMC 2020-04-008). Written informed consent was waived as the data were de-identified in the database used.

\section{Consent for publication:}

Not applicable

\section{Availability of data and materials}

The datasets used and/or analyzed during the current study are not publicly available due to patient data privacy regulations by HIRA.

\section{Conflicts of interest:}

The authors declare that they have no relevant conflicts of interest.

\section{Funding:}

This work was supported by the National Research Foundation of Korea (NRF) grant funded by the Korea government (Ministry of Science and ICT) (No. 2019R1F1A1061841).

\section{Author's contributions:}


Sang Chul Lee contributed to conception and design of the study. Kang Ju Son contributed to data analysis. Chang Hoon Han contributed to critical revision of the paper. Seon Cheol Park and Ji Ye Jung contributed to conception, design, drafting of the article, and critical revision of the paper. All authors agreed to be accountable for all aspects of the work.

\section{Acknowledgments:}

The authors appreciate the contribution of healthcare professionals dedicated to treating SARS-CoV-2 patients in Korea, and the Ministry of Health and Welfare and the Health Insurance Review \& Assessment Service of Korea for sharing invaluable national health insurance claims data in a prompt manner.

\section{References}

1. Zhu N, Zhang D, Wang W, Li X, Yang B, Song J, et al. A Novel Coronavirus from Patients with Pneumonia in China, 2019. N Engl J Med. 2020;382(8):727-33.

2. Organization WH. Coronavirus disease (COVID-2019) situation reports. In; 2020.

3. Chen N, Zhou M, Dong X, Qu J, Gong F, Han Y, et al. Epidemiological and clinical characteristics of 99 cases of 2019 novel coronavirus pneumonia in Wuhan, China: a descriptive study. Lancet. 2020;395(10223):507-13.

4. Guan WJ, Ni ZY, Hu Y, Liang WH, Ou CQ, He JX, et al. Clinical Characteristics of Coronavirus Disease 2019 in China. N Engl J Med. 2020. https://doi.org/10.1056/NEJMoa2002032.

5. Yang J, Zheng Y, Gou X, Pu K, Chen Z, Guo Q, et al. Prevalence of comorbidities and its effects in coronavirus disease 2019 patients: A systematic review and meta-analysis. Int J Infect Dis. 2020;94:91-5.

6. Kew KM, Seniukovich A. Inhaled steroids and risk of pneumonia for chronic obstructive pulmonary disease. Cochrane Database Syst Rev. 2014; https://doi.org/10.1002/14651858.CD010115.pub2. (3):Cd010115.

7. McKeever T, Harrison TW, Hubbard R, Shaw D. Inhaled corticosteroids and the risk of pneumonia in people with asthma: a case-control study. Chest. 2013;144(6):1788-94.

8. Kim MH, Rhee CK, Shim JS, Park SY, Yoo KH, Kim BY, et al. Inhaled Corticosteroids in Asthma and the Risk of Pneumonia. Allergy Asthma Immunol Res. 2019;11(6):795-805.

9. Lee $\mathrm{CH}$, Kim K, Hyun MK, Jang EJ, Lee NR, Yim JJ. Use of inhaled corticosteroids and the risk of tuberculosis. Thorax. 2013;68(12):1105-13.

10. Andréjak C, Nielsen R, Thomsen V, Duhaut P, Sørensen HT, Thomsen RW. Chronic respiratory disease, inhaled corticosteroids and risk of non-tuberculous mycobacteriosis. Thorax. 2013;68(3):256-62.

11. Charlson ME, Pompei P, Ales KL, MacKenzie CR. A new method of classifying prognostic comorbidity in longitudinal studies: development and validation. J Chronic Dis. 1987;40(5):373-83.

12. Asthma Glf. Global strategy for asthma management and prevention. In; 2020. 
13. Suissa S, McGhan R, Niewoehner D, Make B. Inhaled corticosteroids in chronic obstructive pulmonary disease. Proc Am Thorac Soc. 2007;4(7):535-42.

14. Yang $M$, Chen $H$, Zhang $Y, D u Y, X u Y$, Jiang $P$, et al. Long-term use of inhaled corticosteroids and risk of upper respiratory tract infection in chronic obstructive pulmonary disease: a meta-analysis. Inhal Toxicol. 2017;29(5):219-26.

15. Yang $M$, Zhang $Y$, Chen $H$, Lin J, Zeng J, Xu Z. Inhaled corticosteroids and risk of upper respiratory tract infection in patients with asthma: a meta-analysis. Infection. 2019;47(3):377-85.

16. Singanayagam A, Glanville N, Girkin JL, Ching YM, Marcellini A, Porter JD, et al. Corticosteroid suppression of antiviral immunity increases bacterial loads and mucus production in COPD exacerbations. Nat Commun. 2018;9(1):2229.

17. O'Byrne PM, Pedersen S, Carlsson LG, Radner F, Thorén A, Peterson S, et al. Risks of pneumonia in patients with asthma taking inhaled corticosteroids. Am J Respir Crit Care Med. 2011;183(5):58995.

18. Brode SK, Campitelli MA, Kwong JC, Lu H, Marchand-Austin A, Gershon AS, et al. The risk of mycobacterial infections associated with inhaled corticosteroid use. Eur Respir J. 2017;50(3).

19. Yan R, Zhang Y, Li Y, Xia L, Guo Y, Zhou Q. Structural basis for the recognition of SARS-CoV-2 by fulllength human ACE2. Science. 2020;367(6485):1444-8.

20. Hoffmann M, Kleine-Weber H, Schroeder S, Krüger N, Herrler T, Erichsen S, et al. SARS-CoV-2 Cell Entry Depends on ACE2 and TMPRSS2 and Is Blocked by a Clinically Proven Protease Inhibitor. Cell. 2020;181(2):271 - 80.e8.

21. Peters MC, Sajuthi S, Deford P, Christenson S, Rios CL, Montgomery MT, et al. COVID-19 Related Genes in Sputum Cells in Asthma: Relationship to Demographic Features and Corticosteroids. Am J Respir Crit Care Med. 2020. https://doi.org/10.1164/rccm.202003-08210C.

22. Iwabuchi K, Yoshie K, Kurakami Y, Takahashi K, Kato Y, Morishima T. Therapeutic potential of ciclesonide inahalation for COVID-19 pneumonia: Report of three cases. J Infect Chemother. 2020;26(6):625-32.

23. Halpin DMG, Faner R, Sibila O, Badia JR, Agusti A. Do chronic respiratory diseases or their treatment affect the risk of SARS-CoV-2 infection? Lancet Respir Med. 2020;8(5):436-8.

24. Matsuyama S, Kawase M, Nao N, Shirato K, Ujike M, Kamitani W, et al. The inhaled corticosteroid ciclesonide blocks coronavirus RNA replication by targeting viral NSP15. bioRxiv. 2020; https://doi.org/10.1101/2020.03.11.987016.2020.03.11.987016.

25. Yamaya M, Nishimura H, Deng $X$, Sugawara $M$, Watanabe $O$, Nomura K, et al. Inhibitory effects of glycopyrronium, formoterol, and budesonide on coronavirus HCoV-229E replication and cytokine production by primary cultures of human nasal and tracheal epithelial cells. Respir Investig. 2020;58(3):155-68.

26. Janson C, Stratelis G, Miller-Larsson A, Harrison TW, Larsson K. Scientific rationale for the possible inhaled corticosteroid intraclass difference in the risk of pneumonia in COPD. Int $\mathrm{J}$ Chron Obstruct Pulmon Dis. 2017;12:3055-64. 


\section{Supplementary Files}

This is a list of supplementary files associated with this preprint. Click to download.

- COVID19andICSRespiratoryResearchSuppl.docx 